\title{
HVMANITAS
}

\section{Preconceito e ciência: o ataque de Pietro Andrea Mattioli a Amato Lusitano}

Autor(es): $\quad$ Pinto, Antônio Guimarães

Publicado por: Imprensa da Universidade de Coimbra

URL

persistente:

URl:http://hdl.handle.net/10316.2/27420

DOI:

DOI:http://dx.doi.org/10.14195/2183-1718_65_9

Accessed : $\quad$ 26-Apr-2023 15:30:00

A navegação consulta e descarregamento dos títulos inseridos nas Bibliotecas Digitais UC Digitalis, UC Pombalina e UC Impactum, pressupõem a aceitação plena e sem reservas dos Termos e Condições de Uso destas Bibliotecas Digitais, disponíveis em https://digitalis.uc.pt/pt-pt/termos.

Conforme exposto nos referidos Termos e Condições de Uso, o descarregamento de títulos de acesso restrito requer uma licença válida de autorização devendo o utilizador aceder ao(s) documento(s) a partir de um endereço de IP da instituição detentora da supramencionada licença.

Ao utilizador é apenas permitido o descarregamento para uso pessoal, pelo que o emprego do(s) título(s) descarregado(s) para outro fim, designadamente comercial, carece de autorização do respetivo autor ou editor da obra.

Na medida em que todas as obras da UC Digitalis se encontram protegidas pelo Código do Direito de Autor e Direitos Conexos e demais legislação aplicável, toda a cópia, parcial ou total, deste documento, nos casos em que é legalmente admitida, deverá conter ou fazer-se acompanhar por este aviso.

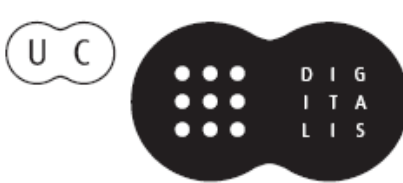


humanitas

Vol. LXV

2013

IMPRENSA DA UNIVERSIDADE DE COIMBRA

COIMBRA UNIVERSITY PRESS 


\title{
CIÊNCIA E PRECONCEITO: O ATAQUE DE PIETRO ANDREA MATTIOLI A AMATO LUSITANO ${ }^{1}$
}

\author{
Antônio Guimarães Pinto
}

Universidade Federal do Amazonas

\begin{abstract}
Resumo
Neste artigo, que decorre da tradução, que acabámos há pouco, do livro que o médico e botânico italiano Pietro Andrea Mattioli escreveu em latim contra o também médico Amato Lusitano, procurámos mostrar como o preconceito religioso e racial, de par com a soberba académica, podem distorcer o rigor e isenção nas ciências mais aparentemente isentas de motivações ideológicas ou nacionais. Numa perspectiva de análise sobretudo literária e histórico-cultural, tentámos provar a falta de probidade científica e seriedade moral com que o conceituado sábio de Siena atacou e procurou destruir a carreira científica, e quem sabe até a própria existência física, do seu colega hebreu-português.

Palavras-chave: Humanismo médico; polémica científica; Amato Lusitano; Mattioli; Dioscórides; anti-semitismo.
\end{abstract}

\footnotetext{
Abstract

Our aim in this article was to show how religious and racial prejudice, in partnership with an oversized academic arrogance, were able to undermine any

1 Este trabalho foi desenvolvido no âmbito do projecto de I\&D "Dioscórides e o Humanismo Português: os Comentários de Amato Lusitano" (http://amatolusitano.web.ua.pt) do Centro de Línguas e Culturas da Universidade de Aveiro, financiado por Fundos FEDER através do Programa Operacional Factores de Competitividade - COMPETE e por Fundos Nacionais através da FCT - Fundação para a Ciência e a Tecnologia, no âmbito do Projecto FCOMP-01-0124-FEDER-009102. O texto deste artigo corresponde em grande parte à comunicação que, sob o mesmo título e em língua espanhola, apresentamos, no dia 18 de maio de 2013, ao "Ciclo de conferências e encontro hispano-luso", intitulado Plantas y Minerales Medicinales: pasado, presente y futuro, que decorreu na Aula Magna da Faculdade de Farmácia de Granada (Espanha). Foi proposto para publicação na Humanitas no dia 14 de Maio e aceite em 15 do mesmo mês.
} 
sense of fairness even in fields pertaining to those sciences more apparently free from ideological or nationalistic motivations. Having just finished a translation of a Latin Apologia, written by the Italian botanist and physician Pietro Andrea Mattioli against his Portuguese contemporary and colleague Amatus Lusitanus, we approached this matter from a literary and cultural point of view, trying to demonstrate the absence of scientific integrity and moral ground of Mattioli's attack, through which this man of science almost destroyed the professional career and possibly tried to put an end to the physical existence of his Hebrew-Portuguese peer.

Key words: Medical Humanism; scientific polemic; Amatus Lusitanus; Mattioli; Dioscorides; anti-semitism.

1.

1.

O Humanismo trouxe, em relação à Escolástica, uma mudança radical nos métodos de controvérsia, que passou a preferir, à frieza impessoal do raciocínio lógico, a subjetividade, por vezes inflamada, do discurso forense. Ao tomar como modelo do estilo latino um autor como Cícero, cuja glória deriva em grande parte da força de um verbo apostado em denegrir, insultar ou exalçar, o Humanismo abria as portas ao tipo de controvérsia que irá desenvolver-se amplamente num século como o XVI, riquíssimo em polémicas de toda a espécie, que se travaram em campos tão diferenciados como a religião, a medicina ou a botânica. Os próprios programas escolares visavam adestrar os estudantes na composição de diatribes e invectivas, prática que não era de molde a criar um espírito de simpatia, ou pelo menos de asséptico interesse intelectual, pelas posições de um oponente, que as mais das vezes era visto como um inimigo que cumpria esmagar mediante todos os processos e técnicas ministrados pelo amplíssimo e inescrupuloso arsenal da retórica.

Curiosamente, o ódio à Escolástica, e, como necessária consequência, aos métodos dialéticos por esta professados, por vezes proclamado como uma das conquistas mais positivas da mudança de mentalidade a que nos referimos sob a designação de Humanismo, deve ter contribuído não pouco para o extremar de posições e para a impossibilidade de compromissos que se tornou inevitável em vários setores da vida moral e intelectual da Europa quinhentista, sobretudo o religioso. De facto, ultrapassando em muito o campo do desacordo ideológico e entrando francamente no 
domínio pessoal, a controvérisa humanística converte-se amiúde numa "arte do insulto". ${ }^{2}$

Bom exemplo desta atitude encontra-se no livro de polémica científica que o médico e botânico italiano Pietro Andrea Mattioli publicou, em 1558, contra o português Amato Lusitano, também médico e botânico. Ora, tanto um como outro, à semelhança do segoviano Andrés de Laguna, de quem também falaremos, se integram naquele interessante grupo humano que o século XVI nos ofereceu e é de uso designar-se por "médicos humanistas", ou seja, homens que, além de se terem consagrado com proficiência ao estudo de um ou de ambos os idiomas clássicos, exerceram influência grande e por vezes benéfica sobre a sua profissão. Eram na sua maioria varões de ampla e variegada cultura, cujos interesses intelectuais se centravam sobretudo na medicina, na literatura e na então chamada história natural.

2.

Pietro Andrea Mattioli foi o mais famoso comentador quinhentista do clássico De materia medica, do grego Dioscórides. Nasceu em Siena, no ano de 1501, e graduou-se em Medicina em Pádua, em 1523. A partir de 1527 passa a residir nas regiões de Trento e Gorizia. Em 1544 publica em Veneza a $1^{a}$ edição da sua obra de maior nomeada: Di Pedacio Dioscoride Anazarbeo Libri cinque Della historia, et materia medicinale tradotti in lingua volgare italiana, mais popularizada pela designação de Discorsi sull' opera di Dioscoride, que é de facto a tradução italiana da obra de Dioscórides, acompanhada de riquíssimos comentários. Lembre-se que por essa época, e após a edição aldina do texto grego original, datada de 1499, já estavam disponíveis as traduções latinas de Jean de la Ruelle, publicada em 1516, e de Hermolao Barbaro e de Marcelo Virgílio.

Em 1548, igualmente em Veneza, appresso Vincenzo Valgrisi, sai uma segunda edição dos Discorsi de Mattioli, enriquecidos com gravuras e incluindo agora, pela primeira vez, o livro $6^{\circ}$ do De materia medica, de duvidosa autoria de Dioscórides. À terceira edição, também veneziana, publicada em 1550, segue-se a edição latina, apud Antonium Vincentium, Veneza: nesta Mattioli segue, corrigindo-o por vezes, o texto latino de Ruelle.

2 Veja-se o que sobre este assunto dissemos nas pp. 231-232 do tomo $1^{\circ}$ da nossa obra Humanismo e Controvérsia Religiosa - Lusitanos e Anglicanos, Lisboa, INCM, 2006. 
Em 1555 muda-se para Praga, onde exerce a função de médico do arquiduque Fernando, filho segundo do imperador seu homónimo, e irmão de Maximiliano II, a partir de 1564 sucessor do pai à testa do Sacro Império Romano-Germânico. Mattioli, depois de alguns anos junto do príncipe Habsburgo, retira-se para Trento em 1571, cidade onde morre, vítima da peste, em Janeiro ou Fevereiro do ano de 1578.

Posto este brevíssimo escorço biográfico, passemos propriamente ao tema que aqui pretendemos desenvolver.

\section{3.}

Na epístola nuncupatória anteposta à $2^{\mathrm{a}}$ edição da sua edição comentada em latim do De materia medica, publicada em 1558, Mattioli agradece a colaboração e louva o saber de Andrés Laguna: Seconbiensem medicum praestantissimum. ${ }^{3}$ Ora, sete anos passados, na $3^{\text {a }}$ edição dos seus Comentários latinos, o nome do espanhol é expungido daquele passo e passa a ser objeto da acerba e irónica crítica seguinte:

Siquidem Andreas a Lacuna superioribus annis non solum in suos in Dioscoride Commentarios, Hispanico idiomate conscriptos, maiorem nostrorum laborum partem transtulit, sed imagines omnes antea a nobis editas, artificum negligentia, et illius parsimonia, adeo deformes reditas, ut nihil natiui splendoris, qui in nostris minoribus elucet, in iis conspici possit. ${ }^{4}$ ["Visto que Andrés Laguna há poucos anos transpôs para os seus Comentários a Dioscórides, escritos em espanhol, não apenas grande parte do meu trabalho intelectual, mas igualmente todas as gravuras que eu anteriormente publicara, de tal sorte desfiguradas, devido à incompetência dos artífices e à sovinice dele, que nelas nada pode vislumbrar-se do original primor que resplandece nas nossas miniaturas."]

Três anos volvidos, formula, em italiano mas quase em termos idênticos, a mesma queixa, na carta dedicatória que precede a edição de 1568 do seu comentário clássico ao De materia medica: il Lacuna nel suo Dioscoride spagnuolo [...] non solamente s' ha servito de miei scritti a sua piacere, ma di tutte le figure delle piante, e degli animali, le quali ha fatte

3 Sobre as relações Mattioli / Andrés Laguna foi-nos guia precioso a monografia de Miguel Ángel GONZÁLEZ MANJARRÉS, Entre la imitación y el plagio. Fuentes e influencias en el Dioscorides de Andrés Laguna, Segovia, Coleccón Becas de Investigación - Caja Segovia, 2000. Veja-se sobretudo o capítulo V, no qual ex professo o Autor se ocupa da matéria que aqui versamos.

4 Praefatio, f. 3 vo. 
intagliare vivamente dalle mie, parendogli (come egli dice) di non averne ritrovato di migliori.

$\mathrm{Na}$ verdade, a mudança brusca na forma como Mattioli conceitua a personalidade e obra de Laguna operou-se em algum momento entre 1558 e 1565, ou seja, num período em que provavelmente o médico segoviano já falecera (1559) e, de qualquer modo, sem que nesse prazo de tempo se tenha verificado qualquer modificação nos termos em que Laguna reconheceu, não apenas a sua irrestrita admiração pelo sábio italiano, como igualmente a sua dívida em relação aos ensinamentos diretamente colhidos na obra deste. Ora, como se sabe, o Pedacio Dioscorides Anezarbeo acerca de la materia medicinal teve a sua $1^{a}$ edição, em Antuérpia, en casa de Iuan Latio, no ano de 1555, e aí, na epístola nuncupatória, o autor espanhol escreveu sem ambages: siruieronme no poco en este trabajo tan importante, los commentarios de Andreas Mattiolo Senes, medico Excellente de nuestros tiempos: el qual con increyble destreza, trasladò el mesmo Dioscorides en lengua Toscana, y le dio grandissima claridad con las singulares expositiones que sobr' el hizo, de las quales nos aprovechamos en algunos lugares de nuestras annotaciones. Com igual lisura, em nota final $A l$ benigno lector, Laguna honestamente confessa: hezimos diligentemente esculpir todas aquellas figuras de nuestro amigo Andreas Mathiolo, que fueron bien entendidas, y sacadas al natural de las verdaderas: porquanto no podian mejorarse.

É verosímil que o assomadiço médico-botânico italiano, ao matutar, alguns anos depois da $1^{\mathrm{a}}$ edição do colega segoviano, com a ranzinzice a que por vezes até alguns sábios são proclives, naquele restritivo aprovechamos en algunos lugares ${ }^{5}$ se tenha sentido algum tanto, se não prejudicado nos seus direitos autorais (conceito então anacrónico), pelo menos menoscabado na

5 Em abono da verdade parece que se pode dizer que Laguna levou longe de mais o aproveitamento que fez do labor do médico italiano. O cotejo a que M. A. GONZALÉS MANJARRÉS procedeu de inúmeros passos das obras do senense e do segoviano levou-o a concluir que este praticou o plágio com uma liberdade que podemos aquilatar de excessiva mesmo para os critérios do século XVI: “en los comentarios de Laguna es posible rastrear sin mucho esfuerzo una marcada huella de los de Mattioli, una gran parte de cuyos datos eruditos hace propios el médico segoviano", o. c., p. 103; "hay algunos pasajes en los que Laguna parece haberse limitado sin más contemplaciones a reproducir literalmente en castellano algunos lugares de los comentarios de Mattioli", o. c., p. 104; "Laguna incluye en sus comentarios determinados datos que parecen originales y propios, pero que en realidad están tomados tácitamente de la obra del autor italiano", o. c., p. 110. 
imagem quiçá superlativa que tinha de si mesmo. Talvez que este episódio, pelos laivos que nos fornece para ajudar a pintar o retrato psicológico e moral de Mattioli, não seja inútil para entendermos a sanha descomedida com que se arremessou contra Amato Lusitano: e dá-nos também ensejo para, em breve parêntese, nos referirmos às relações entre o médico português e o seu colega espanhol, ou, melhor que "relações", e lançando mão do título de um artigo que proficientemente se ocupou deste assunto, el desencuentro de dos humanistas médicos. ${ }^{6}$

\section{4.}

De facto, nascidos no mesmo ano de 1511 em famílias de cristãos-novos peninsulares, tendo coincidido, ainda que brevemente, em torno do ano de 1525, na universidade de Salamanca, tendo-se ambos aplicado à medicina e à botânica com paixão e devotamento, e tendo mantido algum convívio e trato, pelo menos por razões profissionais, na cidade de Roma (nos anos de 1550-1551), a verdade é que todas estas coincidências deram lugar, não a um vínculo estreito ou a recíprocas mostras de amizade, mas a uma obsequiosa deferência e mal disfarçada crítica, da parte do português, ${ }^{7}$ e ao que parece ser uma total ausência de simpatia pelo colega, da parte do espanhol. ${ }^{8}$ Talvez não seja extremada ousadia conjeturar que na origem deste comportamento, que parece refletir uma mútua desconfiança, se encontra o posicionamento religioso que ambos adotaram em relação à religião dos seus maiores: enquanto Amato acaba por abertamente abraçar o judaísmo, Laguna, ainda que professando

6 M. Á. GONZÁLEZ MANJARRÉS e M. J. PÉREZ IBÁÑEZ, "Andrés Laguna y Amato Lusitano, el desencuentro de dos humanistas médicos", L' Universitat de València $i$ l' Humanisme: Studia Humanitatis i renovació cultural a Europa i al Nou Món, Valencia, 2003, pp. 689-711.

7 O sentimento de Amato por Laguna parece bifronte: por uma banda, mostra admirá-lo pelo seu trabalho como coletor e sintetizador da obra de Galeno, mas, pela outra, considera-o como um médico de gabinete, incapaz de adaptar os conhecimentos teóricos à prática clínica. Ou, na síntese dos Autores citados na nota anterior: "la postura de Amato ante Laguna es, al menos, pretendidamente objetiva: reconoce sus méritos cuando así lo cree oportuno, pero no siente reparos en criticarlo siempre que le parece conveniente", o. c., p. 698 .

8 As duas únicas referências valorativas a Amato presentes na obra de Laguna são as seguintes: "Por la qual entiende el Doctor Amado (...) empero sin fundamento" (comentário ao c. 40 do livro $1^{\circ}$ de Dioscórides); "No se en que se funda el Doctor Amado" (comentário ao capítulo 147 do livro $3^{\circ}$ de Dioscórides). 
simpatias erasmianas, manteve-se aparentemente até ao fim da vida dentro da ortodoxia católica. ${ }^{9}$

1.

E é tempo de nos ocuparmos das relações entre as personagens que agora mais diretamente nos interessam: Mattioli e Amato. Ora, como se sabe, entre os comentadores quinhentistas de Dioscórides, cabe um lugar honroso ao albicastrense João Rodrigues, que no mundo das letras adotou o nome de Amato Lusitano. E se esse lugar durante alguns séculos lhe foi injustamente disputado ou, pelo menos, acintosamente obscurecido, tal parece dever-se em grande parte à má vontade e modo ultrajante como o tratou alguém, como Pietro Andrea Mattioli, que na sua época gozou de grande prestígio científico e grande valimento nas altas esferas da política e da religião católica. Tentemos pois descobrir a origem desta sanha do sábio italiano.

Saído de Portugal por volta do ano de 1533 e estabelecendo-se em Antuérpia, primeira etapa de uma vida continuamente errante, Amato publica três anos depois a sua obra de estreia, o Index Dioscoridis, primeira prova do seu interesse pelo livro clássico do sábio grego. Sobre este irá debruçar-se com afinco e erudição nos anos seguintes, oferecendo em 1553 ao público o fruto sazonado de suas investigações: In Dioscoridis (...) de materia medica libros quinque Enarrationes, ["Comentários aos cinco livros de Dioscórides acerca da matéria médica"] impressos em Veneza por Gualtiero Scoto. A obra saiu dos prelos depois de 9 de Março do ano referido, pois tem esta data um poema no qual, em obediência às praxes editoriais de então, se exaltam os merecimentos do autor e do livro. Por sua vez, a dedicatória foi escrita pelo Amato, em Roma, na data já relativamente distante de 15 de Maio de 1551 - ano este, aliás, em que publicara em Florença o $1^{\circ}$ tomo das sete Centúrias de que será autor. Ora, na referida dedicatória das Enarrationes, entre outros estudiosos de quem se confessa devedor, não deixa de citar, no f. V: Matthiolum Senensem, uirum doctissimum: qui nuper Dioscoridem e Latino ethruscum reddit, et

9 Muito de ponderar nos parece a conjetura aventada por M. A. GONZÁLEZ MANJARRÉS e M. J. PÉREZ IBAÑEZ, ao escreverem: "Pero la indiferencia mostrada por Laguna y su voluntaria desmemoria de los tiempos en que Amato y él estudiaron en Salamanca obedecen, posiblemente, a causas religiosas", o. c., p. 711. 
illum commentariis illustrauit. ["Mattioli, de Siena, varão muitíssimo sábio que recentemente traduziu Dioscórides de latim para italiano e o esclareceu com anotações"] Se a curiosidade nos levar a procurar no índice as entradas relativas ao sábio senense, encontraremos os dados seguintes:

Matthioli Senensis error: ["Erro de Mattioli, de Siena"] 9; 32; 36; 47; 68; 76; $100 ; 164 ; 183 ; 252 ; 266 ; 350 ; 362 ; 398 ; 401 ; 421 ; 433$.

Matthiolus Senensis fallitur: ["Mattioli, de Siena, engana-se"] 28; 32; 376; 391; 403.

Matthiolus in distinguendo negligens: ["Mattioli pouco cuidadoso em distinguir"] 28; 32.

Matthiolus Senensis falso Plinium accusat: ["Mattioli, de Siena, acusa falsamente Plínio] 3. Et citat: ["E erradamente o cita"] 471.

Matthiolus Senensis sibi ipsi contradicit: ["Mattioli, de Siena, contradiz-se a si mesmo"] 247.

Matthiolus Theophrastum inepte reprehendit: ["Matthioli critica ineptamente Teofrasto"] 76.

Matthioli Senensis laus: ["Elogio de Mattioli, de Siena"] 368; 381; 397; 431.

Ou seja, ao lado de quatro passagens laudatórias, vinte e oito referências pouco congruentes com o qualificativo doctissimus com que Amato o condecorara na dedicatória do livro: por outras palavras, vinte e oito pungentíssimos golpes no ego de alguém que, conforme insinuámos atrás, parece que se tinha em altíssima conta. Como reagiria o já prestigiado médico-botânico a estas beliscaduras do Lusitano? Ora, a darmos crédito às datas apresentadas na transcrição de Giovanni Fantuzzi, em carta de 13 de Julho de 1553, endereçada ao também botânico e naturalista Ulisses Aldrovandi, Mattioli afiança ao amigo que em breve verá impressa no final da próxima edição do seu Dioscórides latino uma carta apologética escrita contra o médico marrano Amato Lusitano, na qual se defenderá do desaforo cometido pelo português, ao atrever-se a roubar-lhe por inteiro os seus comentários e contra ele escrever em mais de vinte passagens, nas Enarrationes que fizera ao texto do sábio grego. Formula a sua convicção de que, com esta lição exemplar, emudecerá todos os que, como Amato, movidos pela inveja, ladram como cães e se aprestam para atacá-lo, e consigna o propósito de apontar os mais de cem erros em que incorreu aquele fiero mostro ao qual, com grande ferocidade, tenciona quebrar o pescoço. Dali tomará escarmento a turba de invejosos que, contra ele 
incessantemente afiando a malédica dentuça, não se conforma com o saber de tão grande mestre... ${ }^{10}$

Apesar da ameaça, a verdade é que a prometida Apologia, que mais tem carácter de desforço, só verá a luz da publicidade em $1558,{ }^{11}$ ou seja, quando Amato já se encontrava em Ragusa, ${ }^{12}$ a salvo, portanto, da perseguição que desde a subida de Paulo IV ao sólio pontifício (15 de Maio de 1555) se abatera sobre os hebreus que viviam nos Estados Papais, como era o seu caso, que residira em Ancona entre 1540 e 1555 . Aliás, temos forte suspeita de que as malsinações e o clima de surda desconfiança, se não mesmo franca hostilidade, que o Lusitano sentiu em torno de si e o impeliu a abandonar solo italiano, teve na sua origem as maquinações do ódio de Mattaioli, sentimento que não resultaria tanto da discrepância em matéria religiosa, quanto do despeito por ver posta em causa por um quase pária a sua autoridade científica. Lembre-se também que Mattioli é autor de um longo poema em oitavas, em que descreve Il magno palazzo del cardinale di Trento, e, se é certo que as musas o não bafejaram com a inspiração poética, pelo menos não deixaram de lhe imprimir, bem de acordo com a tradição clássica, o genus irritabile uatum...

10 Presto vedrà la S. V. in stampa uma Epistola Apologetica nel fine del mio Dioscoride latino diretta a un certo Amato Lusitano marrano medico al quale non bastando d'avermi rubbato i Comenti tutti integri del mio libro, gl' ha bastato ancor l' animo di scrivermi contra in più de XX. Luoghi in un suo comentuzzo fatto sopra Dioscoride. In questa adonque vederà $V$. S. et tutto il Mondo quanto guadagnino queste maligne persone, che mosse solamente da invidia abbaiano a guisa di cani, et cosi spero che // questa cosa fará tenere la lingua in bocca ai molti, che hora fanno gran promesse d' assaltarmi. Imperochè ivi non solamente difendo la causa mia com eficacissime ragioni, et authorità, a cui non è risposta, ma vi metto purassai comi et parole com tale argutia dette, che rompono il collo del tutto a questo mostro, senza il dimostrar, che io fo com vivissime ragioni di cento et più errori, che egli há fatto: di modo che se questa cosa sarà letta da coloro, che anchora costì lacerano le cose mie, potrebbe essere facilmente, che più per loro interesse, che per cessar dall invidia ammutolissero. Giovanni FANTUZZI, Memorie della vita d' Ulisse Aldrovandi, Bolonha, per le Stampe di Lelio della Volpe, 1774, pp. 155-156.

11 Em outra carta ao mesmo Aldrovandi, datada de 27 de Setembro do mesmo ano de 1553, Mattioli reitera o seu propósito de revidar muito breve ao desacato perpetrado pelo português: Al Lusitano (sia sicura V. S.) che non li mancherò punto, et spero che averà trovato il suo uomo: sebben per esser marrano, et disgratiato, et havermi provocato, non mi par che in modo alcuno se gli abbia aver rispetto. FANTUZZI, o. c., p. 153.

12 Desta cidade-estado adriática, então protetorado do sultão turco, Amato transportar-se-á no seguinte ano de 1559 para território já propriamente otomano, estabelecendo-se em Salónica, onde, segundo BARBOSA MACHADO, Biblioteca Lusitana, sub nomine, virá a falecer em 1568. Para mais detalhes biográficos consulte-se o artigo clássico de Harry FRIDENWALD, "Amatus Lusitanus", Bulletin of the Institute of the History of Medicine, v. 5, n. 7, July 1937, pp. 603-653. 


\section{2.}

Em 1558, da "tipografia erasmiana" de Vincentius Valgrisius e Balthasar Constantinus, em Veneza, sai um livro de 112 folhas impressas não numeradas, cuja página de rosto, além das informações acabadas de apontar, diz o seguinte: Petri Andreae Matthioli, Senensis, serenissimi principis Ferdinandi, archiducis Austriae etc, medici, Apologia adversus Amathum Lusitanum, cum censura in eiusdem Enarrationes. Cum privilegio. ["Defesa de Pietro Andrea Mattioli, de Siena, médico do sereníssimo príncipe Fernando, arquiduque de Áustria etc, contra o português Amathus, com a crítica dos Comentários do mesmo. Com privilégio"] No verso desta página inicial pode ver-se um poema em louvor desta Defesa (ou Apologia, conforme o original latino), em grego, da autoria do boémio Mateus Collinus. Do f. 1 até ao f. $7 \mathrm{r}^{\mathrm{o}}$ derrama-se uma carta, escrita em Viena de Áustria, datada de 2 de Setembro de 1557, e dirigida a Matthioli por Francisco Parthinus, médico de Maximiliano, rei da Boémia, e em breve, pela morte do pai, em 1564 - o imperador Fernando I - destinado a ficar à testa do sacro Império Romano-Germânico como Maximilano II. Do verso do f. 7 até ao verso do f. 10 podemos ler a carta, escrita pelo Autor, em Praga, no dia 29 de Agosto, supomos que do ano da impressão do livro, uma vez que faz referência à carta do médico Parthinus: tem como destinatário Petrus Canizerus, médico-chefe de Fernando Habsburgo, atrás citado, irmão e sucessor de Carlos V como imperador. Nos ff. $11-12 \mathrm{v}^{\circ}$ podemos ler o prefácio do Autor ao leitor. A meio do vo do f. 12 inicia-se propriamente a Defesa contra Amathus, que se compõe da exposição de 20 pretensas calúnias do médico português, a que imediatamente se segue a respectiva refutação. Do f. $48 \mathrm{v}^{\circ}$ até ao $\mathrm{v}^{\mathbf{o}}$ do f. 49 Mattioli espraia-se numa inflamada admoestação ao Lusitano. A segunda parte do livro inicia-se no f. 50 e vai até ao final, no qual (ff. 110 $v^{o}$ a 111) o Autor se regozija com a vitória que supostamente obteve sobre o impertinente inimigo. Está formada esta parte de cem críticas a outras tantas alegadamente erradas identificações relativas a matéria médica apresentadas por Amato, e no número de 100 não podemos deixar de ver o propósito irónico de aludir à série das Centúrias do médico lusitano, que por então se encontravam já na quarta. ${ }^{13}$

13 A $3^{\text {a }}$ e $4^{\mathrm{a}}$ Centúrias tinham sido conjuntamente editadas numa $1^{\mathrm{a}}$ edição saída em Lyon, em 1556, com uma $3^{a}$ edição feita em 1557 pelo editor veneziano Constantinus, que nos aparece também como coeditor da $1^{\text {a }}$ edição da Apologia de Mattioli. 
Como é óbvio, dadas as limitações que, na abordagem deste tema, naturalmente decorrem do tipo de estudos a que nos dedicamos, o nosso propósito não é determinar o valor estritamente científico da argumentação aduzida quer por um quer por outro dos autores, ${ }^{14}$ mas, usando de um critério mais literário e, em sentido lato, histórico-cultural, pretendemos: a) em primeiro lugar, apontar de modo sumário alguns dos processos e técnicas polemísticas de que Mattioli se serviu no sentido de destruir como pessoa e retirar qualquer credibilidade como cientista ao hebreu português Amato Lusitano; b) em segundo lugar, dar, através da exposição e comentário de um exemplo aleatório, uma amostra do método argumentativo com que o Senense fundamenta a sua superioridade científica sobre o opositor.

Que grande parte do livro, publicado depois de 29 de Agosto de 1558, já se encontrava concluída muito antes desta data parecem prová-lo, não só o excerto da carta de Mattioli (aparentemente de Julho de 1553) a Aldrovandi atrás extractado, como também, por um lado, algumas palavras esparsas ao longo da epístola de Francisco Parthinus ao Autor, anteposta à Apologia e datada de Setembro de 1557, e, por outro, outras do botânico de Siena nas páginas proemiais, endereçadas a Petrus Canizerus. São as seguintes as passagens que agora nos interessam do médico do então rei da Boémia:

Iam frequenter ad me delatum foret te Apologiam quam contra hunc ineptum hominem institueras, pariter et Censuras in eius grauissima errata paene ad finem perduxisse. [f. $1 \mathrm{v}^{\circ}$ ] ["Já amiúde eu fora informado de que quase concluíras uma Defesa, que te decidiras a escrever contra este homem inepto, juntamente com as Críticas aos seus gravíssimos erros"]; Scimus iam hanc operam a te incoeptam, plus increbuit hic rumor quod latius et liberius hunc calcographus dissiparit. [f. 6] "Sabemos que já iniciaste esta obra, rumor este que mais aumentou por o impressor o ter espalhado mais extensa e livremente"]; Emitte quod iam penes te habes paratum. [f. 6] "Publica o já em teu poder tens pronto"]

14 Numa perspectiva exclusivamente científica, e seguindo sobretudo uma abordagem descritiva dos conteúdos, José María VALDERAS consagrou ao livro de Mattioli os dois seguintes artigos: "La polémica en la investigación botánica del siglo XVI. Mattioli contra Lusitano", Collectanea Botanica (Barcelona) 25, 2 (2000), pp. 255-304; "Mattioli contra Lusitano. II. Las 'censuras' y la interpretación de Dioscórides", Collectanea Botanica (Barcelona) 26, 1 (2003), pp. 181-225. 
Mattioli, por sua vez, assim fala sobre as delongas verificadas na publicação do seu trabalho crítico, ajuntando também os motivos que acabaram por decidi-lo a levar a cabo uma empresa sobre cuja utilidade sentia hesitações:

Quod cum tandem fecissem, dubius subinde distrahebatur // animus an quam confeceram Apologiam una cum Censuris in eius deliramenta in lucem proferrem, an vero diutius domi nostrae premerem. [f. 8 vo-9] [“Tendo finalmente levado a cabo esta tarefa, o meu espírito depois duvidava // sobre se deveria publicar juntamente com as Censuras aos delírios do homem uma Defesa que eu redigira, ou se a reteria durante mais tempo comigo"]; Dum anceps in his versor opinionibus (...) // et ubi potius negotium hoc honeste subterfugere cupiebam quam exsequi, tot accesserunt doctorum virorum suasiones, tot amicorum litterae, tot calcographi nostri preces, tot quorumdam allatae rationes ut tandem (quamquam fere invitus) decreverim eorum potius sequi sententiam quam meam. [9-9 $\mathrm{v}^{\circ}$ ] [“ao tempo em que me acho duvidoso (...) // e quando mais desejava esquivar-me honestamente a este encargo do que cumpri-lo, sobrevieram tantos discursos de persuasão de varões sábios, tantas cartas de amigos, tantos rogos do meu impressor, tantos motivos apresentados por certas pessoas que, ao cabo, (embora quase que contra a minha própria vontade) decidi antes seguir a opinião destes que a minha"]; nullus mihi sese obtulit qui animum magis vinceret meum quam Franciscus Parthinus $\left[9 \mathrm{v}^{\circ}\right.$ [ ["não houve ninguém que mais dobrasse o meu espírito do que Francisco Parthinus"]

Ora, vai ser este mesmo Francisco Parthinus quem nos oferecerá o diapasão pelo qual irá afinar toda a extensa invectiva mais ou menos erudita do médico de Siena, e que soa destarte:

Excute istum scarabeum ex tuis floribus nec sinas ut suis molestissimis susurris et foetore ista contaminet ex quibus optima et roscida mella reliqui se confecturos // sperant. [f. 5-5 v $v^{\circ}$ [ "Enxota esse escaravelho do meio das tuas flores e não deixes que com os seus importuníssimos zumbidos e fedor contamine esses escritos com que os demais esperam vir a confeccionar o mais excelente e fresco mel"]

$\mathrm{Na}$ base de todo o descomedimento e procacidade demonstrados por Pietro Andrea Mattioli no livro escrito contra Amato Lusitano talvez se encontrasse um espírito algum tanto inseguro sobre os seus reais merecimentos, e que, como meio de defesa, acudiria ao recurso de autovalorizar-se de forma 
superlativa e ver na mais ligeira beliscadura ao seu renome e autoridade um inadmissível atentado, mobilizador de todo o arsenal a que uma psique padecendo deste tipo de perturbação ordinariamente lança mão: ou seja, os expedientes do insulto em todas as suas modalidades. Corrobora-nos nesta suspeita um dos sintomas típicos deste tipo de desequilíbrio e ao qual a experiência nos mostra que os académicos são sobremaneira achacados: a mania persecutória, que, além dos significativos passos já citados das cartas a Aldrovandi, julgamos poder comprovar-se com os passos seguintes:

Nisi incredibili arderes libidine nostros oppugnandi labores. [f. 25] [“Se não te abrasasses nesse mórbido desejo de atacar os meus trabalhos"]; fortasse puduisset ita te iniuria in me conspirasse. [f. 26] ["talvez sentisses pejo por tão injustamente teres conspirado contra mim"]; apertam in nos invidentiam. [f. 29] ["o ódio declarado que me vota"]; cum is ad nostros perdendos labores invidentia ac livore se totum accinxerit. [f. 48] ["uma vez que ele se dispôs inteiramente a, por ódio e inveja, destruir os meus trabalhos"]; qui suis iniquissimis calumniis honestissimos labores nostros opprimere nititur [f. 50] ["o qual com as suas injustíssimas calúnias se esforça por destruir os meus trabalhos"]; Redit austerus et immitis censor: virgam, vel fustem potius, profert. [f. 93] ["Regressa o crítico ríspido e impiedoso: mostra a vara, ou melhor, o varapau"]

2.3.

Passaremos agora a um breve conspecto dos processos e técnicas de insulto de que deitou mão a sanha de Mattioli, reconhecendo de antemão que os subtítulos ou categorias por que repartimos os exemplos, bem como estes, estão longe de ser exaustivos.

\section{Raça e religião}

Antes de mais convém registar que, na nota marginal que acompanha a $1^{\text {a }}$ das citações que vão seguir-se, Mattioli achou por bem consignar o seguinte esclarecimento étnico-lexical: Lusitanus semiidaeus. Hispani tales Marranos vocant, quos maxime detestantur. ["O Lusitano é meio-judeu. Os hispânicos chamam a tais criaturas marranos, e têm-lhes grande ojeriza"]

Te caecum dico ea tantum ratione quod a Deo immortali perfidissime desciscas. Etenim cum (ut audio) nunc nostrae religionis te ipsum facias, nunc Iudaicis legibus superstitionibusque te totum addicas et ita non solum in homines, sed in ipsum Deum Optimum Maximum insolescas, minime id 
est mirum si a te ipso quoque deficias et omni statu mentis dimovearis. Vt non // modo in te nulla vigeat pietas, nulla religio, verum et in ipsa medica facultate, quam immerito profiteris, plurimum caecutias.[ff. 48 vo-49] ["estás cego unicamente por, com a maior das deslealdades, teres abandonado Deus imortal. É que, uma vez que (segundo ouço dizer), ora te finges seguidor da nossa religião, ora inteiramente te consagras às leis e superstições judaicas, e deste modo te ensoberbeces não só contra os homens, mas também contra Deus Nosso Senhor, não é de espantar se também te afastas de ti mesmo e te apartas de toda a coerência mental. Para que, não // só falte em ti qualquer sentimento de respeito pelas coisas elevadas e qualquer religiosidade, mas também careças de vista na própria medicina, que indevidamente professas"]; quase mecum de religione contendat, quam homo inconstans iampridem turpissime ac impudentissime deseruit. [f. 12 $\mathrm{v}^{\mathrm{o}}$ ] ["como se disputasse comigo sobre a religião, que a inconstante criatura já há muito tempo de forma infame e impudentíssima abandonou']; cum nostram et suam religionem omni flagitio polluerit, dedecore maculaverit, scelere obligaverit et eam tantum ob causam e sua exsulaverit Lusitania. [f. $14 \mathrm{v}^{\mathrm{o}}$ ] ["a verdade é que manchou a nossa e sua religião com toda a espécie de ignomínias, a maculou com a infâmia e com o crime a comprometeu, e só por esse motivo foi proscrito do seu Portugal']; a propósito das cebolas ascalónicas, comenta: Equidem putabam haec non ignorasse Lusitanum, cum illum compertum habeam oriundum a locis quibusdam non procul ab Ascalone Iudeae... [f. $81 \mathrm{v}$ ] ; ["Ora, eu pensava que o Lusitano não desconhecia isto, pois descobri que ele é originário de certos lugares não longe de Ascalon, na Judeia...']; magis Lusitanus lege percitus Mosaica quam veritatis sustinendae. [f. $70 \mathrm{v}$ ] ["o Lusitano, mais entusiasmado com a lei de Moisés do que com a verdade"]; depois de ter citado as palavras de Amato, em que este, a propósito de um tratamento, se referira quamdam suae gentis mulierem, Beatricem a Luna vocatam ["a uma certa dama muitíssimo nobre da sua raça, chamada Beatriz de Luna'], Mattioli, em tom francamente depreciativo, refere-se a esta nos termos seguintes: Nihil ad me attinet de illa, quam adducit, muliercula. [f. 64] ["Nada tenho a ver no que tange a essa mulherzinha que ele alega"]

\section{Arrogância e suficiência displicente}

Is rationibus argumentisque nostris, nullis prorsus obstet verbis nec ulla dicendi facultate (si philosophum medicumque, ut audio, se putat) [f. 28] ["ele aos meus argumentos e razões não os contraria com palavras 
absolutamente nenhumas nem com qualquer talento oratório, se, conforme ouço dizer, se tem na conta de filósofo e médico"]; si (ut audio) Graeci sermonis peritum se ipsum facit, maximo illi vitio adscribendum fuerit [f. $44 \mathrm{v}^{\circ}$ ] ["se (conforme ouço dizer) ele se faz passar por muito entendido em língua grega, deve ser-lhe imputada como enorme falha"]; istius temerarii hominis imperitiam ac neglegentiam aperire [f. 75 v"] ["pôr a nu a ignorância e negligência desse homem desatinado"]; Mihi non leve fuit incommodum cum huius frivolis ineptiis colluctari. [f. $110 \mathrm{v}$ ] ["não foi para mim pequeno incómodo defrontar-me com as fúteis inépcias deste homem"]; hoc sum conatus, ut non solum se reprehendi doleat, sed et suae confidentissimae imperitiae ipsum iure paeniteat. Quin etiam ut sciat ac noscat se errorum Centurias fecisse. [f. 111] ["o meu empenho foi que ele não só sofra por ser repreendido, mas com justiça se arrependa da sua insolente ignorância. E saiba e reconheça que cometeu centúrias ${ }^{15}$ de erros"]

\section{Insulto direto}

Amatho quodam Lusitano, homine sane, ut eius fert nomenclatio, apprime indocto [f. $8 \mathrm{v}^{\circ}$ ] ["um certo Amathus Lusitano, homem, na verdade, sumamente ignorante, como assoalha o seu próprio apelativo"]; ex quibus tu // opima spolia congessisti. Egregiam certe hominis in furando prudentiam, ut tacite iis secum gaudeat quae publice criminari putetur. Idcirco, homo vaferrime [f. 31 vo-32] ["das obras de Mattioli, das quais tu // retiraste montes de despojos. Grande esperteza, sem dúvida, nas artes da roubalheira deste homem, que lhe permite desfrutar à puridade daquelas coisas em relação às quais faz acusações caluniosas. É essa a razão, ó mestre dos velhacos"']; In confesso est omnibus hominis huiusce scripta sui ipsius esse figmenta, mendacia, vanitates, adeo ut iam omnibus stomachum commoverint. [f. 36] ["é incontestável para todos os homens que os escritos desta criatura são invenções, mentiras e falsidades só dele próprio, a tal ponto que já a toda a gente causam engulhos"]; tenere me non potui quin in vehementem solverer cachinum. (...) Serione haec dicuntur ab Amatho? An risum sua vecordia movere studet? Nimirum adducor ut credam (...) aliquo amentiae genere illum quandoque vexari et proinde tunc temporis nonnisi huiusmodi deliramenta describere. [f. 69] ["não pude ter-me que não desatasse às gargalhadas. (...) Amathus profere estas coisas a sério? Ou com a sua sandice

15 Alusão irónica à série de obras médicas do autor português, aliás abertamente alfinetada em outros passos da Apologia. 
pretende provocar o riso? Sou levado a crer (...) que por vezes ele é atacado por alguma casta de loucura e por isso durante algum tempo só escreve delírios desta laia."]; Lusitanus dicat, qui sua singulari amentia (...) discat etiam a circulatoribus [f. $80 \mathrm{v}^{\circ}$ ] ["Que no-lo diga o Lusitano, que com a sua singular loucura (...) aprenda também com os charlatães"]; no seguinte passo, a invectiva consorcia-se com a imodesta autocomplacência: innumeris et turpissimis istius hominis erratis. Quae si nuda in medio ponerem, cui non ista stomachum moveant? Nunc ita uniuscuiusque occurrere studeo prudentiae // ut non parum hoc quemque consolari debeat, quod, in huius refrenanda audacia, plura interim a nobis afferuntur non infrugifera et (nisi me spes fallit) non indigna eruditis auribis. [ff. 75 v -76] ["incontáveis e vergonhosos erros deste homem. Se eu os mostrasse a nu, a quem não causariam engulhos? Agora por tal maneira me empenho em ir ao encontro do bom senso de cada um // que não deve consolar pouco a quem quer que seja o facto de que, ao refrear o atrevimento deste homem, do mesmo passo vou referindo muitas coisas não infrutíferas nem (se a esperança não me engana) indignas de ouvidos sábios"; illico frivolam et stolidam nimis, ut ceteras omnes, opinionem induit Lusitanus. [f. 98] [“o Lusitano adota sem detença uma opinião tola e de sobejo estólida, como todas as outras suas"]; a propósito do qualificativo "sicofanta" (impostor, denunciante) com o qual Amato mimoseara o botânico Luigi Mondella, Mattioli revida com inflamada fúria: Tu, mihi crede, potius Sycomoros appellandus fueris, cum tantum ad amentias et fatuitates te procreaverit natura, illum vero ad totius rei publicae commodum. Depone istam mentem, desine, impudentissime, isto modo doctissimos viros lacessere. Omnes qui istam in te audient ingratam contumaciam (...) nonne stolidum, vecordem, insanum et omni mentis statu dimotum te iudicabunt? [f. $101 \mathrm{v}^{\circ}$ ] [“Tu, e acredita no que te digo, mais merecias que te chamassem sicómoro, uma vez que a natureza te criou só para a tolice e a sandice, ao passo que a ele para proveito da comunidade inteira. Põe de parte esse teu sestro, deixa, ó grande desavergonhado, de atacar por essa forma os varões mais sábios! Todos os que ouvirem falar em relação a ti dessa tua obstinada ingratidão (...) acaso não hão-de julgar que és estúpido, desvairado, maluco e completamente privado de todo o equilíbrio mental?']

\section{Ironia e sarcasmo}

Tiresia vel talpa caecior sit [f. $39 \mathrm{v}^{\circ}$ ] ["é mais cego do que Tirésias ou de que uma toupeira"]; fortasse Lusitanus sincero careat gustu, perinde 
ac iudicio [f $46 \mathrm{v}^{\mathrm{o}}$ ] ["é possível que o Lusitano esteja privado de genuíno gosto, tal como de juízo"]; nulla mihi amplius est contentio medico, verum cum sollertissimo degustatore, vel coquo potius [f. 71] ["a minha contenda já não é com um médico, mas com um refinadíssimo gourmet, ou melhor, um cozinheiro"]; Equidem censebam utero tantum gerentes mulieres citta picaque corripi posse. Sed (ut video) Amathus etiam eo morbo laborabat, quod fortasse ob multam praestitam in re medica operam et ob magnas illas Centurias adeo intumuerit ut praegnanti similis evaserit; vel quod fortasse Coriandri tantum inter olera esitaverit in Hispania, eius saporis odorisque praestantia allectus, ut inde facile amentiam contraxerit, quam facere Coriandrum scribit Dioscorides, ubi largius assumatur in cibum.[f. $90 \mathrm{v}^{\circ}$ ] ["Eu pensava que só as mulheres grávidas podiam sentir desejos por coisas impróprias para comer. Mas (consoante vejo) o Amathus também padecia desta perturbação, talvez por, devido à muita atividade desenvolvida na medicina e por causa daquelas grandes Centúrias, de tal sorte ter inchado que ficou semelhante a uma mulher prenhe; ou talvez por na Península Ibérica, seduzido pela excelência do sabor e cheiro dele, ter abusado tanto do coentro entre as verduras que com isso facilmente contraiu a loucura, que Dioscórides escreve que o coentro provoca, quando se toma como alimento imoderadamente"]; Tiresia caecior fuerit [f. $104 \mathrm{v}$ ] [ "foi mais cego do que Tirésias"]; tamquam caecus iudicet de coloribus [f. 104 vo] ["fala como um cego acerca de cores"]; At Lusitanus, qui longe potius Oedipum quam medicum profitetur [f. $108 \mathrm{v}^{\mathrm{o}}$ ] ["Mas o Lusitano, que se apresenta muito mais como Édipo do que como médico"]

\section{'Graças, chistes, motes, facécias, bufonerias'16}

Nesta rubrica se integra de pleno direito e em primeiro lugar a acintosa e cruel distorção mediante a aqual Mattioli procurou achincalhar e destruir o médico português através da marca mais óbvia da identidade de alguém: o nome próprio. Assim, sem que qualquer precedente anterior o justificasse, Mattioli decidiu dar à grafia do nome Amatus, ${ }^{17}$ assim sistematicamente utilizada pelo meu compatriota, a forma corrupta Amathus, de modo a

16 Pe António Vieira.

17 Como se sabe, o nosso Autor só em 1551 parece ter-se decidido a trocar o seu nome de batismo João por este Amado ou Amatus, que, segundo conjetura plausível citada por Harry FRIEDENWALD, o. c., p. 606, seria a recuperação, em chave latina, do original sobrenome hebraico da sua família: Habib. 
associá-lo com o adjetivo grego 'amathês', "demente, ignorante". Que a sua malévola intenção é esta demonstra-o, entre outros, o passo já citado da sua epístola proemial: Amatho quodam Lusitano, homine sane, ut eius fert nomenclatio, apprime indocto. [f. $8 \mathrm{v}^{\circ}$ ] [“certo Amathus Lusitano, homem, na verdade, sumamente ignorante, como assoalha o seu próprio apelativo"]

Trocadilhos: 1) o que resulta, por um lado, da confusão entre a palavra grega e o nome do português a ela arbitrariamente ligado e, por outro, da paronímia em latim entre os nomes Lusitanus e lusciosus ('zarolho, cegueta'): Amatho amentior et Lusitano lusciosior fuerit qui non noverit [f. 68] ["é mais demente que o Amathus e mais zarolho que o Lusitano quem não souber"]; 2) a paronímia que lhe permitiu associar, com propósitos grotescos, mos ('costume, uso'), a moria ('sandice, loucura'): sed suo more (prope dixerim moria) [f. 17] ["mas como nele é de uso (estava a ponto de dizer de iluso"]

Hipérbole burlesca: Timendum, nisi hanc oculorum curet caliginem, ne culicem pro cane, vel fortasse etiam équo accipiat. [f. $56 \mathrm{v}^{\circ}$ ] "Se não trata desta névoa nos olhos, é de recear que tome um mosquito por um cachorro, ou talvez até por um cavalo"]

Onomatopeia: Ah ah ah! Prae risu scribere fere nequimus. [f. 65] ["Ah ah ah! Com o riso quase não consigo escrever"]

1.

Passaremos agora, consoante prometemos, à transcrição e análise de uma das entradas críticas de Mattioli, escolhida de modo aleatório - no caso vertente, pertencente à $2^{a}$ parte do seu trabalho, aquela em que faz a crítica de 100 pretensamente erradas identificações feitas por Amato -, e que nos servirá para mostrar, por uma parte, a linguagem, as fontes e os processos de trabalho de que se serve o médico-botânico italiano, e, por outra, comentar e contextualizar a informação transmitida pelo médico-humanista português. Cremos que as conclusões a extrair desta análise e cotejo poderão ser extensivas à totalidade do livro-invectiva de Mattioli, ou seja, de molde a fundamentarem a nossa convicção de que o sábio italiano não procedeu com a ponderação e equilíbrio que legitimamente esperaríamos de alguém que se nutriu do saber clássico e, movido por paixões demasiado humanas, se valeu de todos os recursos que a retórica ou os preconceitos da época 
(inclusive o racial e religioso) punham à sua disposição para aniquilar uma pessoa que, embora pontualmente e de forma relativamente comedida, ousara levantar algumas objeções a uma autoridade que provavelmente se presumia indiscutível. Oiçamo-lo, pois, no original latino:

[f. 59]

LACCA ARABVM

Consultum longe melius (mea quidem sententia) fuisset Lusitano, si poeticae potius quam medicae facultati se totum addixisset; nam, qui eo in effingendis fabulis aptior promptiorque se praestituerit, video profecto neminem. Id enim omnibus palam fiet diu in re medica versatis qui diligenter istius intuebuntur Centurias, in quibus innumera sese offerunt figmenta, adeo rem seriam prae se ferentia ut ea quis difficillime fabulas esse noscat, nisi medicae facultatis fuerit recte peritus.

Verum, cum ad hoc illum natura pepererit, mirandum sane non est si a fabulandi facultate discedere nequeat, sed potius illi venia danda, quippe qui id propria agat natura, qua in praesentia ductus, de Mauritanorum Lacca scripturus, evadere non potuit quin fabulosi aliquid admisceret his verbis: "Qui huc usque Cancamum Laccam esse putarunt, miro errore deprehenduntur, cum Cancamum Gummi odoriferum sit, Lacca vero sive mansa, sive suffimentis explorata, inodora percipitur. Quam hodie Lusitani ex India afferunt, rubram, translucidam, $\left[\mathbf{v}^{\mathbf{0}}\right]$ tincturis praecipue deservientem et ex ea officinae compositionem quamdam praeparant, Dialaccam appellatam, quae (ut certo scimus) non gummi aut arboris plantaeve alicuius gutta est, sed potius formicarum alatarum stercus favagoque, velut cera apum. In regno igitur Pegu dictu apud Indos, cum terra vel pluvia vel arte plus iusto irrigatur, formicae praedictae ligna quaedam subtilia ab incolis disposita in altum ascendunt, in quibus Laccam generant, et hac de causa in Lacca ligna ipsa percipimus, quae dubio procul arboris non sunt Laccam ferentis, ut hucusque omnes fere crediderunt." Haec illius est fabula. Atqui illi maxime refragatur Ludovicus ille Romanus, libro sexton sua navigationis, ubi de his agit aromatis ac mercimoniis, quae Sumatra insula sive Taprobana mittit, sic inquiens: "Mittit etiam ea regio Laccam, unde conficiunt rutilum colorem. Gignitur haec in arbore iuglandibus nostris haud absimili." Haec illi, cui subscribit Ioseph Indus, capite CXLI, ubi fatetur in Cambaia Laccam uberius nasci quam alibi gentium, non autem fieri gignive formicis aut scarabaeis, ut lepidius et facetius quam verius fabulatur Lusitanus.

[60*] Praeterea, cum duplex sit Lacca, quae Alexandria Aegypti Venetias comportatur, altera lignis quibusdam inhaerens Sumatri, a Sumatra fortasse 
insula nuncupata, altera Cambaiti, a Cambaia denominata, in glebas Myrrhae instar concreta, nulli inhaerens ligno, non est cur Lusitani fabulam historiam putem. Siquidem gleba illa Sole clarius palam facit Laccam gummi esse arboris, non quidem, ut per somnium vidit Lusitanus, formicarum alatarum stercus, quibus etsi ubique scateat tota Europae regio, nusquam tamen visae sunt alatae formicae, quae Laccam aut simile aliud excernerent.

Ceterum, cum satis superque nobis comprobatum sit in Commentariis in Dioscoridem editis Mauritanorum Laccam et Graecorum Cancamum esse idem, adeo ut pluribus id comprobare testimoniis non sit opus, cadit peritque Lusitani sententia, quam sequi nemo debet.

Ou seja, em nosso vernáculo lusitano:

[8 ${ }^{a}$ crítica:] LACA DOS ÁRABES

Em minha opinião, o Lusitano teria tomado uma deliberação muitíssimo melhor se se tivesse consagrado inteiramente antes à poesia do que à medicina; é que vejo que não existe ninguém mais apto e rápido do que ele para inventar fábulas. De facto, isto tornar-se-á manifesto a todos os que versam há muito tempo a medicina e que diligentemente puserem a vista nas Centúrias desse homem, nas quais se oferecem inúmeras fantasias, apresentando-se de tal maneira como coisa séria que com muita dificuldade quem quer que seja as reconhecerá como fábulas, a menos que tenha uma correta prática e experiência de medicina.

Mas, uma vez que a natureza o deu à luz para este ofício, não é de espantar se não pode desviar-se da faculdade de inventar, mas antes cumpre desculpá-lo, visto que tal é obra da própria natureza, guiado pela qual, ao tencionar escrever sobre a laca dos Mouros, não pôde evitar misturar nas seguintes palavras algo de fabuloso:

Os que até hoje pensaram que o cancamum é a laca foram senhoreados por um erro enorme, uma vez que a goma cancamum é cheirosa, ao passo que a laca quer mastigada, quer usada para defumações, é inodora. A que os Portugueses hoje trazem da Índia, vermelha, $\left[\mathbf{v}^{\mathbf{0}}\right]$ translúcida, útil sobretudo para a tinturaria e com a qual as boticas preparam um certo composto, chamado dialaca, que (como sabemos sem margem para dúvidas) não é uma goma ou exsudação de alguma árvore ou planta, mas sim excrementos e favago, semelhante à cera das abelhas, segregado por formigas aladas. Por conseguinte, no chamado reino de Pegu, na Índia, quando ou devido à chuva ou artificialmente a terra fica com mais água do que o normal, as referidas formigas sobem uns certos paus delgados postos assim ao alto pelos 
habitantes, nos quais depositam a laca, e por esta razão vemos a própria madeira na laca, que sem dúvida não é de árvore que produza laca, como até hoje quase todos acreditaram.

É esta a historinha dele. Mas a ele sobretudo se opõe o célebre Ludovico Romano, no livro $6^{\circ}$ da sua navegação, onde trata destas especiarias e mercadorias que produz a ilha de Sumatra ou Taprobana. São estas as suas palavras: "Esta região produz a laca, com que preparam a cor vermelho-vivo. Nasce numa árvore não diferente das nossas nogueiras." Com ele concorda o José Indiano, no capítulo 141, onde afirma que em Cambaia nasce laca mais abundantemente que em qualquer outro lugar, mas não que é feita ou segregada por formigas ou escaravelhos, ${ }^{18}$ consoante fabulou o Lusitano com mais gaiatice e espírito zombeteiro do que verdade.

[60*] Além disso, uma vez que existem duas qualidades de laca, que se exporta de Alexandria no Egito para Veneza, uma, aderida a certas madeiras, chamada sumatri, talvez por causa da ilha de Sumatra, e a outra designada cambaiti, a partir do nome Cambaia, condensada em bolas, como a mirra, não estando aderida a nenhuma madeira, não há motivo para que eu considere história verídica a fábula do Lusitano. Visto que aquela bola prova mais claramente que o Sol que a laca é uma goma de árvore, e não, como o Lusitano viu em sonhos, excrementos de formigas aladas, as quais, embora abundem por toda a parte na Europa, todavia em lugar algum se viram formigas aladas que evacuassem laca ou cousa similar.

De resto, uma vez que, nos Comentos a Dioscórides que editei, assaz e de sobejo eu provei que a laca dos Mouros e o cancamum dos gregos são a mesma coisa, de tal maneira que não se faz mister provar isso com mais testemunhos, cai por terra e desvanece-se a opinião do Lusitano, que ninguém deve seguir.

Mattioli, antes de entrar propriamente em matéria, prepara o terreno procurando destruir a autoridade do adversário recorrendo à ironia e reduzindo Amato à condição de um fabulador impenitente, com maiores possibilidades de êxito como poeta do que como médico. Aproveita-se aqui o ensejo para

18 José Indiano limitou-se a dizer, tal como Matthioli transcreve, que ibi lacha nascitur uberius quam alibi gentium (f. 78). A inferência negativa em relação aos insetos é, pois, embora plausível (dado o emprego do verbo nascitur), da inteira responsabilidade do sábio italiano. 
ridicularizar as Centúrias, série de literatura médica, de que (como atrás dissemos) até à data tinham saído três volumes, nos quais Amato expusera e comentara inúmeros casos clínicos com que se defrontara na sua longa e prestigiada carreira profissional.

O médico-botânico italiano transcreve em seguida as palavras do colega português, que procedem da p. 42 da $1^{\text {a }}$ edição das Enarrationes e constituem a enarratio ou comentário 23, intitulado De cancamo. Em abono da verdade, cumpre reconhecer-se que as transposições das palavras do autor português, aqui como em todo o livro, são feitas com exação, salvo pequenas alterações de forma: como é caso, neste exemplo, da substituição de commansa por mansa, experta por explorata, apium por apum e da supressão do possessivo nostri que se segue a Lusitani.

Depois da frechada peçonhenta com que retoma a palavra ("É esta a historinha dele"), Mattioli opõe à exposição de Amato a citação de dois autores que, dado o seu suposto conhecimento das regiões orientais, donde procedia o produto em discussão, deveriam com o peso da sua autoridade provar o nenhum crédito a conceder-se às palavras do nosso compatriota. Ora, a verdade é que Mattioli estriba-se na conhecida relação das viagens do aventureiro bolonhês (a que por engano chama romano) ${ }^{19}$ Ludovico de Varthema, cuja $1^{a}$ tradução latina data de 1511 , e aos 13 capítulos atribuídos a um sacerdote nestoriano, designado como José Indiano, acompanhante de Pedro Álvares Cabral no regresso da viagem deste à Índia, que fazem parte de uma popular coletânea coletiva, pela primeira vez publicada em italiano no ano de 1507, com o título de Paesi nouamente retrovati, e cuja tradução latina se editou em Milão no ano seguinte sob a designação de Itinerarium Portugallensium e Lusitania in Indiam et inde Occidentem et demum ad Aquilonem. Em boa verdade, prima facie não nos ofereceriam excessivas garantias de crédito, não só os termos com que estes autores se exprimem, como muito menos a minguada ou nula autoridade que é razoável atribuir-lhes nestas matérias da então chamada história natural. E, de facto, o modo vago como tanto o viajante bolonhês, cuja passagem pelo oriente foi fugaz e no caso particular da laca parece faltar de outiva, como as palavras do sacerdote nestoriano, que se limita a dizer que "em Cambaia nasce laca mais abundantemente do que

19 Qualificação que se manteve na tradução para castelhano, saída dos prelos sevilhanos do impressor alemão Jacobo Cromberger, em 1520, com o título de Itinerario del venerable varon micer Luis, patricio romano. 
em qualquer outro lugar" - e note-se que a ilação que imediatamente se segue no texto da Apologia (i. e., "mas não que é feita ou segregada por formigas ou escaravelhos") é da exclusiva autoria de Mattioli -, estão longe de oferecer-nos o carácter de verdade inconcussa que o Senense atribui à sua identificação do cancamum com a laca.

\section{2.}

Se procurarmos, porém, fundamentos para a afirmação de Amato, objeto do remoque acerado de Mattioli, talvez nos firmemos na convicção de que "a historinha" do médico de Castelo Branco tem todos os visos de verosímil, o que aliás seria de esperar da parte de alguém em condições especialmente privilegiadas, como eram as suas, no que tange a receber da origem informações sobre a fauna e flora orientais, se pensarmos na sua qualidade de português, por um lado, e de cristão-novo, por outro, situação esta em particular que implicava o acesso a uma vasta rede de contactos, em que muitos dos nós pertenciam à classe dos mercadores de drogas ou às dos boticários e dos médicos-botânicos. Ora, a esta última pertencia o celebérrimo Garcia da Orta, cujo memorável livro, impresso por Ioannes de Endem, saiu a lume em Goa, em 1563, precisamente dez anos depois das Enarrationes, com o título de Colóquios dos simples e drogas e cousas medicinais da Índia e assi de alguas frutas achadas nela, onde se tratam alguas cousas tocantes à medicina prática e outras cousas boas pera saber. O colóquio 29 desta obra, travado da p. 122 à 129 entre os interlocutores Orta e Ruano, tem como título "O lacre", nele se expondo o que podemos presumir ser então a última palavra sobre a laca ou lacre e suas possíveis relações com o cancamum. Vejamos o que o experiente sábio português, após longa estadia no oriente, concluiu a este respeito.

Depois de começar por dizer que "chama-se o lacre, que nós nos livros da botica chamamos laca, em arábio e pársio e turquisco locsemutri, casi lacre de Samatra" [f. $122 \mathrm{v}^{\circ}$ ], refere as sucessivas fases por que passou o seu conhecimento da laca / lacre, até chegar ao estado de certeza que o livro reflecte: "Muito tempo fui enganado, porque diziam que em Pegu saíam os rios de madre, e que na lama que ficava punham paus pequenos, e que ali se criavam ũas formigas muito grandes com asas que avoavam e punham o lacre muito nos paus, e que por isso havia lacre muito nos paus metido" [f. 123]; "até que falou comigo um homem bem criado que lá estivera, e era curioso, e me dixe que era um árvore grande em cantidade, com folhas que pareciam de amexueira, e 
que lavravam nos ramos pequenos daquele árvore este lacre as formigas gran-//des criadas na vasa e em outras partes, e que tiravam deste árvore como de causa material esta goma, lavrando no pau como a abelha faz no mel, e que esta era a verdade, e que depois tiravam os ramos daquela árvore em pedaços e os punham a secar à sombra até que despediam o pau e ficava em canudos, e em alguns deles ficava o pau metido dentro, e quanto menos pau tem deste se há por melhor" [ff. 123-123 vº; "e despois mandei saber a Pegu e achei ser muita verdade" [f. $123 \mathrm{v}^{\circ}$ ]; "e aqui em Goa (...) muitos me dexeram que o viram nas maceiras e que as formigas o geravam nele, e é craro ser isto verdade porque muitas vezes vem as asas das formigas mesturadas no lacre, e este lacre de que falamos quando é mastigado tinge de fino roxo" [f. $123 \mathrm{v}^{\circ}$ ].

Mais à frente, criticando a opinião de Avicena, que, por ignorância, identificara a árvore da mirra com a da laca, escreve: "sei que a goma do lacre é feita per cima dos paus forrando-o, e a outra é estilando-se do árvore, e a mirra tem cheiro, e // o lacre não o tem" [ff. 124-124 v']. Acresce e importa salientar a informação que Orta dá sobre o monopólio da comercialização deste produto, que, pelos vistos, se encontrava em meados do século XVI em mãos exclusivamente lusas: "porque o lacre não o vendem senão pegus aos portugueses, e nós o vendemos aos arábios e turcos e o levamos a Portugal, onde se gasta para África e outros cabos" [f. $121 \mathrm{v}^{\circ}$ ].

Finalmente, a respeito da identificação entre o cancamum e a laca, que Mattioli tão veementemente propugnara, Garcia de Orta pronuncia-se nestes termos: "Avicena creu que o lacre era o cancamo de Dioscórides (...) e craramente consta ser falso, porque o nosso lacre carece de cheiro e o cancamo é cheiroso e auto pera perfumes" [f. $121 \mathrm{v}^{\circ}$ ]. Mais à frente, nas palavras seguintes quase nos sentimos tentados a ver, naquele vago outros, uma alusão à pedanteria livresca do Senense: "sabeis que o lacre é este que vedes ir da Índia a Portugal (...) e por vós não terdes que o é nem os frades nem outros não se mudam as cousas do que são, e digo, como já dixe, que Serapio se enganou crendo ser o cancamo de Paulo e de Dioscórides" [f. 126 $\left.\mathrm{v}^{\circ}\right]$. Aliás, o grande botânico alentejano exprime, com as cautelas e ressalvas do verdadeiro sábio, a sua opinião sobre o controverso cancamum, confessando ao seu interlocutor Ruano: "eu vos direi qual é o cancamo segundo // meu parecer, posto que pera concruir isto não tenha rezões evidentes: mas quem me der outras milhores, estou aparelhado pera aprovar o contrairo. (...) [o cancamo] é anime, porque é bom pera cheiro e em perfumes usado, e vem a Portugal de Etiópia (terra confim a Arábia).” [ff. 126 v-127] 


\section{3.}

Para remate deste excurso, diga-se que a botânica e química de hoje nos ensinam que a chamada 'goma laca' é uma substância resinosa que se acumula nos ramos de algumas árvores da Índia, Tailândia e Birmânia (país este que corresponde ao Pegu dos nossos autores do século XVI), resultante da quase contínua excreção de um pequeno inseto, chamado cochonila da laca, ou, cientificicamente, laccifer lacca, que, em estado de larva, nas árvores onde, em enormes quantidades, os seus ovos foram depositados, insere uma probóscide e segrega um revestimento protetor - a goma ou resina laca -, que consiste numa escama vermelho escuro e outra substância amarelo-avermelhada.

Posto isto, podemos concluir que a fantasia de Amato Lusitano não se deixava levar por voos tão arrojados e insensatos como o atilado Mattioli não trepidou em assacar-lhe.

\section{4. CONCLUSÃO}

Com a precedente exposição julgamos ter deixado claro que Pietro Andrea Mattioli, sábio notável e expositor competente a quem a botânica muito deve, não teve a grandeza de alma suficiente para se defender dos supostos plágios e ofensas do médico português Amato Lusitano com a objetividade, senso de equilíbrio e respeito pela opinião alheia que nós hoje reputamos inseparável do exercício de qualquer atividade de pesquisa académica, e que, apesar das grandes diferenças que nos apartam da mentalidade quinhentista, mesmo assim acharíamos razoável encontrar em alguém que abundantemente se abeberou na cultura clássica. Vimos também que as observações críticas que Amato expendeu a respeito do italiano nas Enarrationes ou "Comentários" a Dioscórides, publicados em 1553, desencadearam uma reação desproporcionada ao tom do português, o qual, conquanto tenha posto em causa algumas afirmações de Mattioli, manteve sempre uma linguagem comedida e urbana: ainda que também nos pareça evidente que, por trás desta polidez cortical, latejava um tal ou qual irónico desafio à autoridade do médico-botânico bem posicionado e acatado pelas autoridades académicas, civis e religiosas.

Aliás, este excesso no revide já tivera pelo menos um precedente, a que também aqui aludimos, no tratamento desabrido com que o italiano se 
referiu ao segoviano Andrés Laguna, a quem, com linguagem destemperada, acusou de plágio descarado, sem embargo do reconhecimento público que, na sua tradução comentada de Dioscórides, Laguna fez da grande dívida que contraíra ao aproveitar-se de muito do material carreado pelo botânico de Siena. Ora, o descompassado destas reações parece configurar uma personalidade que a si mesma se tem na mais alta conta e que vê em qualquer observação crítica, e mesmo sujeição mitigada (seria o caso de Laguna, que se atreveu a não confessar que devia "tudo" ao italiano), um inadmíssivel atentado contra o seu ego.

Conforme vimos, o desforço contra o suposto desaforo do português só teve expressão pública com a edição da Apologia em 1558, ou seja, cinco anos após o "atentado" perpetrado com a publicação das Enarrationes, embora saibamos que, poucos meses volvidos sobre esta, já confessava, a um correspondente epistolar, o seu desígnio de defender-se por escrito do ultraje. É, porém, do mais elementar bom senso conjeturar que durante esse lustro o Senense não deixaria, entre o seu vasto e influente círculo de conhecimentos, de dar largas à sua ojeriza e despeito: período de tempo esse, é bom não esquecer, que coincidiu com a violenta campanha anti-semita que se desencadeou em Itália, e, sobretudo, nos Estados Papais, com a eleição, em Maio de 1555, de Paulo IV para o sumo pontificado da Igreja católica. Vimos também que na sua Apologia Mattioli deitou mão de grande parte dos recursos retóricos usuais na polémica ideológica ou doutrinal quinhentista, mas que acrescentou este já rico arsenal com o apelo ao preconceito anti-semita, de modo e em circunstâncias, aliás, que implicavam uma positiva ameaça para a segurança física do visado.

Postas estas premissas e contexto, poderíamos extrapolar da situação de antagonismo pessoal que este caso aparentemente reflecte, e, como conclusão, ser tentados a ver na sanha de Mattioli contra o Lusitano um eco da pugna a que o século XVI assistiu entre os "homens da escritura", de que fala o nosso Épico, ${ }^{20}$ e o novo conhecimento direto da "natura" a que, com humildade, nos quatro cantos do mundo se entregaram os povos peninsulares, tão desdenhosamente tratados pelo homem de Siena.

20 Cf. Os Lusíadas, 5. 22. 7-8: Vejam agora os sábios na escritura // Que segredos são estes da natura. 